\title{
MORPHOLOGICAL STUDY OF ATTACHMENT OF COSTOCLAVICULAR LIGAMENT ON THE CLAVICLE IN SOUTH INDIAN POPULATION
}

\author{
Pretty Rathnakar', Remya $K^{2}$, Chaitra $D^{3}$, Swathi ${ }^{4}$, Vishal Kumar ${ }^{5}$, Anuja Sinha ${ }^{6}$ \\ ${ }_{1}^{1}$ Associate Professor, Department of Anatomy, K. S. Hegde Medical Academy, Deralakatte, Mangalore, Karnataka, India. \\ ${ }_{2}^{2}$ Lecturer, Department of Anatomy, K. S. Hegde Medical Academy, Deralakatte, Mangalore, Karnataka, India. \\ ${ }^{3}$ Tutor, Department of Anatomy, K. S. Hegde Medical Academy, Deralakatte, Mangalore, Karnataka, India. \\ ${ }^{4}$ Associate Professor, Department of Anatomy, K. S. Hegde Medical Academy, Deralakatte, Mangalore, Karnataka, India. \\ 5 Professor and HOD, Department of Anatomy, Kodagu Institute of Medical Sciences, Madikeri, Kodagu, Karnataka, India. \\ ${ }^{6}$ Assistant Professor, Department of Anatomy, K. S. Hegde Medical Academy, Deralakatte, Mangalore, Karnataka, India.
}

ABSTRACT

\section{BACKGROUND}

Clavicle is an important bone concerned with movements of upper limb. It has a shaft and two ends, sternal end and acromial end. Inferior surface of the sternal end presents with an impression called costoclavicular area. The presence of costoclavicular groove for the attachment of costoclavicular ligament was studied in 78 clavicles. The most common type seen was rough and elevated. This area is clinically important for radiologists and orthopaedicians.

Aim- To study the attachment of costoclavicular ligament on clavicle.

\section{MATERIALS AND METHODS}

A cross-sectional descriptive study was carried on 78 clavicles, out of which 27 were of right side and 51 belonging to left side of unknown age and sex. The impressions for the attachment of costoclavicular ligament were observed. Bones were obtained from the Department of Anatomy, K. S. Hegde Medical Academy, Deralakatte, Mangalore. The results were tabulated and percentages were calculated.

\section{RESULTS}

Inferior surface of sternal end of clavicle provides attachment for costoclavicular ligament. The impression is well-demarcated from the rest of the bone in most of the cases and invariably oval in outline and showed distinctive types of surface projection. In this study 78 clavicles comprising of 27 right and 51 left were taken and impressions were noticed, i.e. flat and smooth (FS), rough and elevated (RE), depressed and rough (DR), flat and rough (FR) and no impression. We found 6 (6.4\%) flat and smooth (FS), 38 $(48.7 \%)$ rough and elevated (RE), $23(29.5 \%)$ depressed and rough (DR) and 6 (6.4\%) flat and rough (FR) impressions on the clavicle. Out of 78 clavicles, 5 of them had no impressions.

\section{CONCLUSION}

The most common type of pattern of attachment of costoclavicular area on the clavicle is rough and elevated. The knowledge of morphological variation of costoclavicular impression area is clinically useful for radiologists and orthopaedicians.

\section{KEY WORDS}

Clavicle, Costoclavicular Area, Sternal End and Acromial End.

HOW TO CITE THIS ARTICLE: Rathnakar P, Remya K, Chaitra D, et al. Morphological study of attachment of costoclavicular ligament on the clavicle in South Indian population. J. Evolution Med. Dent. Sci. 2018;7(33):3684-3686, DOI: $10.14260 /$ jemds/2018/827

\section{BACKGROUND}

Clavicle is an important bone concerned with movements of upper limb. It has a shaft and two ends. The lateral end of it will articulate with acromion process of scapula and form acromioclavicular joint. The lateral third has two surfaces, an upper and a lower; and two borders, an anterior and a posterior. The medial two-thirds constitute the prismatic portion of the bone, which is curved so as to be convex in front, concave behind and is marked by three borders, separating three surfaces.

'Financial or Other Competing Interest': None.

Submission 04-07-2018, Peer Review 29-07-2018,

Acceptance 03-08-2018, Published 13-08-2018.

Corresponding Author:

Remya K,

Lecturer, Department of Anatomy,

K. S. Hegde Medical Academy,

Deralakatte, Mangalore-575018,

Karnataka, India.

E-mail: remyavinod35@gmail.com

DOI: $10.14260 /$ jemds $/ 2018 / 827$

\section{(c) (i) $(9)$}

The borders are the anterior, superior and posterior border. Posterior border is also known as the subclavian border. It separates the posterior surface from the inferior surface, and extends from the coracoid tuberosity to the costal tuberosity. It forms the posterior boundary of the groove for the subclavius and gives attachment to a layer of cervical fascia, which envelops the Omohyoideus. In the medial part of the inferior surface is the costal tuberosity or rhomboid impression, more than $2 \mathrm{~cm}$ in length and gives attachment to costoclavicular ligament. This bone is prone to fractures, particularly in young active adults. These fractures are common injuries accounting for $2.6 \%$ of all fractures.(1) Costoclavicular ligament is one of the ligamentous structure that stabilises the sternoclavicular joint.(2,3) It extends from the first costal cartilage and the adjoining part of the first rib to the inferior surface of medial part of the shaft of the clavicle.(4) There is a risk of injury to this ligament in people of certain occupation like painters and construction workers.(5) Hyperostotic changes in the medial end of the clavicle can involve this ligament.(6) 
The course of the subclavian vein, which is posterior to costoclavicular ligament makes it crucial while placing pacemakers and venous catheters. $(7,8,9)$ The impression on the costoclavicular ligament area on the clavicle can vary. Sometimes, it can be a tuberosity.(5) Otherwise, it may be a rough impression or a rough oval depressed area.(10,11) In early primates the costoclavicular ligament was not a separate entity, but it was continuous with sternoclavicular joint capsule.(12) A flat area on the rib at the site of attachment of costoclavicular ligament indicates an absence of the ligament. In these cases, it can be assumed that the costoclavicular ligament is not a separate entity and instead is a part and parcel of capsule of sternoclavicular joint.

\section{MATERIALS AND METHODS}

A descriptive study was carried on 78 clavicles, out of which 27 was of right side and 53 belonging to left side of unknown age and sex. The impressions for the attachment of costoclavicular ligament was observed. Bones were obtained from the Department of Anatomy, K. S. Hegde Medical Academy, Deralakatte, Mangalore. The results were tabulated and percentages were calculated.

\section{RESULTS}

Inferior surface of sternal end of clavicle provides attachment for costoclavicular ligament. The impression is welldemarcated from the rest of the bone in most of the cases and invariably oval in outline and showed distinctive types of surface projection. In this study 78 clavicles comprising of 27 right and 51 left were taken and impressions were noticed, i.e. flat and smooth (FS), rough and elevated (RE), depressed and rough (FS), flat and rough (FR) and no impression. We found 6 (6.4\%) flat and smooth (FS), 38 (48.7\%) rough and elevated (DE), 23 (29.5\%) depressed and rough (DR) and 6 (6.4\%) flat and rough (FR) impressions on the clavicle. Out of 78 clavicles, 5 of them had no impressions.

\begin{tabular}{|c|c|c|c|}
\hline Type of Impression & Right (\%) & Left (\%) & Total (\%) \\
\hline $\mathrm{F}$ and $\mathrm{S}$ & $0(0)$ & $6(11.76)$ & $6(7.6)$ \\
\hline $\mathrm{R} \mathrm{a}$ & $14(51.9)$ & $24(47.1)$ & $38(48.7)$ \\
\hline $\mathrm{D}$ and $\mathrm{R}$ & $9(33.3)$ & $14(27.4)$ & $23(29.5)$ \\
\hline $\mathrm{F}$ and $\mathrm{R}$ & $3(1$ & $3(5.8)$ & $6(7.6)$ \\
\hline No $\operatorname{Im}$ & & 41 & 5 \\
\hline Total & $27(34.6)$ & $51(65.4)$ & $78(100.0)$ \\
\hline \multicolumn{4}{|c|}{$\begin{array}{l}\text { Table showing the distribution of the Side and Type of } \\
\text { Impression on the Clavicle }\end{array}$} \\
\hline
\end{tabular}

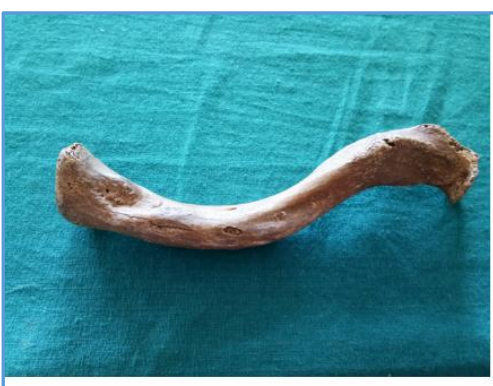

DEPRESSED AND ROUGH

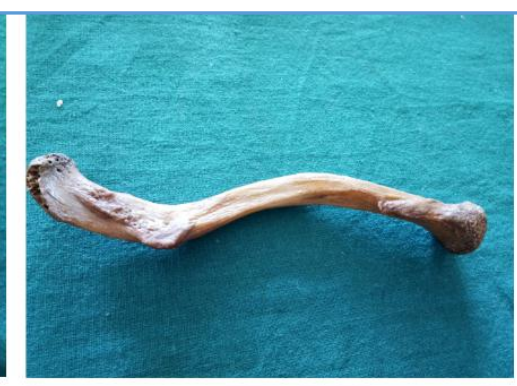

FLAT AND ROUGH

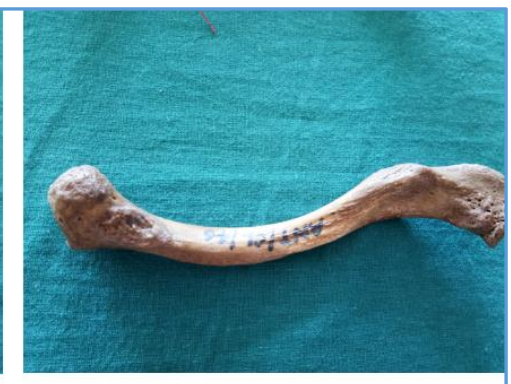

ELEVATED AND ROUGH

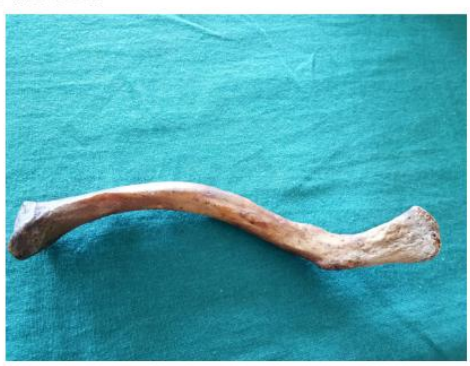

NO IMPRESSION

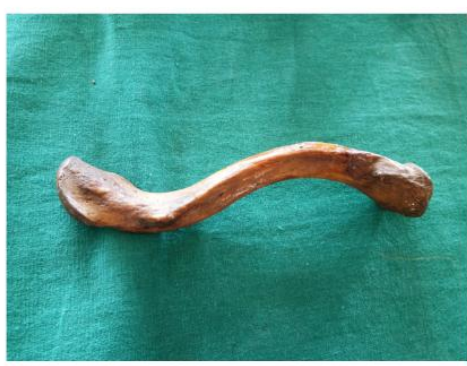

FLAT AND SMOOTH

\section{DISCUSSION}

There are a variety of possible patterns of attachment area of costoclavicular ligament. It may be depressed and rough, flat and rough, elevated and smooth, elevated and rough, flat and smooth or depressed and smooth. Diagnostic errors can result from a lack of knowledge of the differences in the attachment area of costoclavicular ligament. Rhomboid fossa, a depressed and rough area can be mistaken for benign fibrous dysplasia or chronic osteomyelitis.(13) In our study, the most common observation was rhomboid fossa. Rhomboid fossa was the most common finding in a study conducted at Lucknow by Anita Rani and Co in clavicles of Indian origin.(14)
In their study on ribs, the corresponding area of attachment of costoclavicular ligament on first rib was either flat or elevated and was uncircumscribed; therefore, no shape could be attributed to them. Majority of impressions on first rib as well as on ossified first costal cartilage were of elevated and rough type, which were congruent with the most common type of impression on clavicle, i.e. depressed and rough. Our study was also in agreement with a previous study conducted by Jit and Kaur, where they studied 789 clavicles in Indians.(15) The presence of rhomboid fossa is correlated with the age and sex of the individual by many workers. [16,17] Paraskevas et al found $26.88 \%$ incidence of excavated type of rhomboid fossa in a study on 80 chest radiographs. They found higher incidence of fossa on right side in right-handed 
person and on left side in left-handed person, so they proposed mechanical theory for the formation of fossa.(18) Presence of faceted apophysis on clavicle, first rib and ossified first costal cartilage strongly suggest the existence of a diarthrodial articulation at the attachment area of costoclavicular ligament. While studying the morphological features of area of attachment of costoclavicular ligament on 153 clavicles of European origin, Cave et al observed smooth, elevated, circumscribed facet like area in $2.6 \%$ cases and regarded it as evidence of existence of synovial variety of costoclavicular joint.(13) The incidence of depressed and rough area was very less (18\%) in this study.

\section{CONCLUSION}

The most common type of pattern of attachment of costoclavicular area on the clavicle is rough and elevated. The knowledge of morphological variation of costoclavicular impression area is clinically useful for radiologists and orthopaedicians.

\section{List of Abbreviations}

1. FS- Flat and Smooth.

2. RE- Rough and Elevated.

3. DR- Depressed and Rough.

4. FR- Flat and Rough.

\section{REFERENCES}

[1] Standring S. Grays Anatomy. 39th edn. Elsevier Churcill Livingstone 2008.

[2] Neer C. Fractures of the clavicle. In: Rockwood CA, Green DP, eds. Fractures in adults. $2^{\text {nd }}$ edn. Philadelphia: JB Lippincott 1984: p. 707-13.

[3] Rowe CR. An atlas of anatomy and treatment of midclavicular fractures. Clin Orthop Rel Res 1968;58:29-42.

[4] Renfree KJ, Wright TW. Anatomy and biomechanics of the acromioclavicular and sternoclavicular joints. Clinical Sports Med 2003;22(2):219-37.

[5] Spencer EE, Kuhn JE, Huston LJ, et al. Ligamentous restraints to anterior and posterior translation of the sternoclavicular joint. J Shoulder Elbow Surg 2002;11(1):43-7.

[6] Robinson CM, Jenkins PJ, Markham PE, et al. Disorders of the sternoclavicular joint. J Bone Joint Surg Br 2008;90(6):685-96.
[7] Schaeffer's JP. Osteology. In: Morris' Human Anatomy: a complete systematic treatise. $10^{\text {th }}$ edn. Philladelphia: The Blakiston Company 1942: p. 187.

[8] Shimizu T, Chigira M. Roentgenological analysis of sternocostoclavicular hyperostosis by computed tomography. J Jpn Orthop Assn 1989;63(1):18-24.

[9] Krutchen AE, Bjarnason H, Stackhouse DJ, et al. The mechanisms of positional dysfunction of subclavian venous catheters. Radiology 1996;200(1):159-63.

[10] Magney JE, Flynn DM, Parsons JA, et al. Anatomical mechanisms explaining damage to pacemaker leads, defibrillator leads and failure of central venous catheters adjacent to the sternoclavicular joint. Pacing Clin Electrophysiol 1993;16(3 Pt 1):445-57.

[11] Harada Y, Katsume A, Kimata M, et al. Placement of pacemaker leads via the extra thoracic subclavian vein guided by fluoroscopy and venography in the oblique projection. Heart Vessels 2005;20(1):19-22.

[12] Frazer JE. The anatomy of the human skeleton. $4^{\text {th }}$ edn. London: J \& A Churchill Ltd., 1948.

[13] Cave AJE. The nature and morphology of the costoclavicular ligament. J Anat 1961;95:170-9.

[14] Rani A, Chopra J, Rani A, et al. A study of morphological features of attachment area of costoclavicular ligament on clavicle and first rib in Indians and its clinical relevance. Biomedical Research 2011;22(3):349-54.

[15] Jit I, Kaur H. Rhomboid fossa in the clavicles of North Indians. Am J Phys Anthropol 1986;70(1):97-103.

[16] Prado FB, de Mello Santos LS, Caria PHF, et al. Incidence of clavicular rhomboid fossa (Impression for costoclavicular ligament) in the Brazilian population: Forensic application. J Forensic Odontostomatol 2009;27(1):12-6.

[17] Rogers NL, Flournoy LE, McCormick WF. The rhomboid fossa of the clavicle as a sex and age estimator. J Forensic Sci 2000;45(1):61-7.

[18] Paraskevas G, Natsis K, Spanidou S, et al. Excavatedtype of rhomboid fossa of the clavicle: a radiological study. Folia Morphol (Warsz) 2009;68(3):163-6. 